\title{
FORMAÇÃO E DISTRIBUIÇÃO DO PLEXO BRAQUIAL EM PAPAGAIOS VERDADEIROS (Amazona aestiva, Linnaeus, 1758)
}

\section{DEVELOPMENT AND DISTRIBUTION OF THE BRACHIAL PLEXUS IN BLUE-FRONTED PARROT (Amazona aestiva, Linnaeus, 1758)}

\author{
Rayssa Marley Nóbrega da Silva ${ }^{1}$ \\ Paula de Oliveira Figueiredo ${ }^{1}$ \\ Marcelo Ismar Santana ${ }^{1^{*}}$ \\ ${ }^{1}$ Universidade de Brasília, Faculdade de Agronomia e Veterinária, Brasília, DF, Brasil. \\ *Autor para correspondência - misantana@unb.br
}

\section{Resumo}

Procedimentos anestésicos locais são realizados comumente em aves domésticas e silvestres, por ser de baixo custo e de rápida indução, desde que feitos com precisão, o que requer conhecimento anatômico específico da área a ser operada. Este trabalho objetivou estabelecer a origem e a distribuição do plexo braquial do papagaio verdadeiro (Amazona aestiva), através da dissecação da pele e da musculatura de 22 papagaios (17 machos e 5 fêmeas), provenientes do Centro de Triagem de Animais Silvestres do Distrito Federal, após óbito motivado por causas naturais, promovendo o isolamento das raízes formadoras do plexo braquial, bem como de sua ramificação. O plexo braquial foi formado através de quatro troncos, envolvendo os ramos ventrais dos segmentos medulares de C9 a C10, C10 a C11, C11 a T1 e T1 a T2, que se uniram em um curto tronco comum, ramificado em cordões dorsal e ventral. O tronco comum emitiu os delgados nervos subcoracóide e subescapular, além do ramo para o músculo escapuloumeral. O cordão dorsal deu origem aos nervos anconeal, axilar e radial, e o cordão ventral, os nervos peitoral cranial, peitoral caudal, coracobraquial e medianoulnar, cujos ramos supriram os músculos dos compartimentos extensor e flexor do membro torácico, músculos peitorais e pele sobrejacente.

Palavras-chave: asa; aves; inervação; psitacídeos; sistema nervoso periférico.

\begin{abstract}
Local anesthetic procedures are commonly used in domestic and wild birds, because of its low cost and fast induction, as long as applied with great precision, which requires specific anatomical knowledge of the site of incision. This study aimed to establish the origin and distribution of the brachial plexus of the Blue-fronted Parrot (Amazona aestiva) by anatomic dissection of the skin and musculature of 22 specimens (17 males and 5 females) from the Wild Animals Screening Center of the Federal District after death by natural causes. The dissection work promoted the isolation of the forming roots of the brachial plexus, as well as its ramifications. The brachial plexus was formed by four trunks, including the ventral spinal cord rami segments from $\mathrm{C} 9$ to $\mathrm{C} 10, \mathrm{C} 10$ to $\mathrm{C} 11, \mathrm{C} 11$ to $\mathrm{T} 1$
\end{abstract}


and $\mathrm{T} 1$ to $\mathrm{T} 2$, which joined into a short common trunk, branched into dorsal and ventral cords. The thin nerves subcoracoideus and subscapularis and the branch to the scapulohumeralis muscle originated from the common trunk. The dorsal cord originated the anconeal, axillaris and radialis nerves, while the ventral cord gave origin for the pectoralis cranialis, pectoralis caudalis, coracobrachialis and medianoulnaris. These branches innervated the muscles of the extensor and flexor compartments of the forelimb, pectoral muscles and overlying skin.

Keywords: birds; innervation; peripheral nervous system; psittaciformes; wing.

Recebido em: 24 fevereiro 2015

Aceito em: 27 abril 2015

\section{Introdução}

O Brasil é o país com a maior diversidade de psitacídeos do mundo, abrigando 72 espécies reconhecidas, sendo 52 registradas somente na floresta amazônica ${ }^{(1)}$. Dentro do gênero Amazona, o papagaio verdadeiro (Amazona aestiva, Linnaeus, 1758) é uma das espécies mais populares como animal de estimação, além de ser a mais encontrada em zoológicos brasileiros, apesar de a maioria dos exemplares ser proveniente do tráfico de animais silvestres ${ }^{(2)}$.

Essa crescente popularidade, bem como o aumento do interesse pela conservação de aves silvestres, tem criado exigências quanto à obtenção de informações especializadas por parte de médicos veterinários $^{(3)}$, o que reafirma a necessidade de maiores estudos sobre esta espécie. Além do mais, existe para as aves uma grande preocupação com a redução da mortalidade e morbidade durante a realização de procedimentos anestésicos, já que não se sabe precisamente quais são as doses e o tempo de efeito dos anestésicos locais nas diferentes espécies ${ }^{(4-6)}$.

Apesar do pequeno número de trabalhos relacionados ao uso desses anestésicos em aves silvestres, seu uso é vantajoso devido ao baixo custo e rápida indução, mas que deve ser administrado com precisão para que possa promover analgesia adequada, requerendo dessa forma, conhecimento anatômico preciso da área a ser utilizada ${ }^{(7,8)}$. Neste caso, variações anatômicas nos diversos grupos taxonômicos de aves podem dificultar o acesso aos nervos nas diferentes regiões corporais e gerar falha no bloqueio anestésico ${ }^{(9)}$, tornando importante a realização de estudos referentes à origem e distribuição dos plexos nervosos, principalmente por serem raros em aves, sobretudo as da fauna brasileira $^{(10,11)}$.

Portanto, frente à escassez de dados sobre anatomia do papagaio verdadeiro, o presente trabalho pretendeu elucidar a composição anatômica do plexo braquial, buscando estabelecer a origem e a distribuição dos nervos constituintes para o membro torácico, por meio de um estudo macroscópico.

\section{Material e Métodos}

Foram utilizados 22 exemplares de papagaios verdadeiros (Amazona aestiva, Linnaeus, 1758), todos adultos (dezessete machos e cinco fêmeas) e provenientes do Centro de Triagem de Animais Silvestres do Distrito Federal, doados congelados após óbito motivado por causas naturais. O projeto foi aprovado pela Comissão de Ética no Uso de Animais do Instituto de Ciências Biológicas 
da Universidade de Brasília, sob o número 52097/2011.

Após serem fixados em solução aquosa de formol a 10\%, realizou-se a dissecação da origem do plexo braquial e sua distribuição. Para tanto, foi feita incisão do revestimento cutâneo e da tela subcutânea da região axilar, seguido da remoção do osso esterno, juntamente com os músculos peitoral e supracoracóideo, por meio da secção das costelas, ossos coracóides e clavícula. Em seguida, realizou-se a retirada do tecido adiposo e dos músculos hipaxiais da coluna vertebral cervical e torácica, possibilitando visualizar individualmente as vértebras e os ramos ventrais que compõem o plexo braquial, isolando-os das demais estruturas vasculares.

Os nervos identificados foram fotografados para documentação (Figuras 1 a 4), estando a nomenclatura utilizada de acordo com a Nômina Anatômica Aviária ${ }^{(12)}$.

\section{Resultados}

O plexo braquial do papagaio-verdadeiro foi originado a partir da medula espinhal, oriundo de ramos ventrais dos nervos espinhais cervicais e torácicos, formando quatro troncos nervosos em 95,45\% dos casos (21 aves) ou três troncos em 4,55\% dos casos (uma ave), em ambos os antímeros. Em 19 papagaios $(86,4 \%)$ com onze vértebras cervicais, o primeiro tronco originou-se dos espaços intervertebrais de $\mathrm{C} 9$ a $\mathrm{C} 10$, o segundo tronco de $\mathrm{C} 10$ a $\mathrm{C} 11$, o terceiro tronco de $\mathrm{C} 11$ a $\mathrm{T} 1$, enquanto o quarto tronco originou-se de T1 a T2 (Figura 1). Em apenas um papagaio (4,6\%), também com onze vértebras cervicais, foram encontrados três troncos originados de $\mathrm{C} 9$ a $\mathrm{C} 10, \mathrm{C} 10$ a $\mathrm{C} 11$ e C11 a T1, respectivamente.

Em duas aves que apresentaram doze vértebras cervicais, o primeiro tronco originou-se dos espaços intervertebrais de $\mathrm{C} 9$ a $\mathrm{C} 10$, o segundo tronco de $\mathrm{C} 10$ a $\mathrm{C} 11$, o terceiro tronco de $\mathrm{C} 11$ a $\mathrm{C} 12$, enquanto o quarto tronco originou-se de $\mathrm{C} 12$ a T1.

Em sua trajetória, as raízes do plexo braquial passaram pelos forames intervertebrais, atravessando a musculatura cervical para formar curtos troncos, que se combinaram dentro da cavidade celomática em um tronco comum, mais espesso. O primeiro tronco (C9 a C10) foi o único que emitiu nervo de forma isolada, o supracoracóideo, pouco antes de sua fusão com as raízes ventrais dos demais troncos (Figura 1).

Após sua formação, o tronco comum deixou a cavidade celomática através de um pequeno hiato situado na parede corporal, entre a margem ventral da escápula, a face caudal do osso coracóide e a margem cranial da primeira costela, e se subdividiu imediatamente em um delgado ramo que originou os nervos subcoracóideo, subescapular e um delicado ramo muscular para o músculo escapuloumeral caudal, além de dois cordões nervosos de mesma espessura, um dorsal e outro ventral.

A partir do cordão dorsal (Figura 1), observou-se a formação do nervo anconeal, que se separou do cordão principal distalmente ao início do nervo radial, para seguir pela margem caudal do músculo escapuloumeral caudal, em direção ao músculo tríceps escapular, inervando-o bem como o músculo tríceps umeral. O nervo axilar (Figura 1) deixou a axila proximalmente ao nervo radial, onde se curvou cranialmente ao terço proximal do músculo escapuloumeral caudal, entrando profundamente no braço, para inervar os músculos tríceps umeral e tríceps escapular com delgados ramos musculares, bifurcando-se em seguida em ramos proximal e distal. Os ramos terminais do nervo axilar contornaram lateralmente o músculo tríceps umeral, sendo que o ramo proximal inervou o 
músculo deltoide e a articulação escapuloumeral, enquanto o delgado ramo distal, o nervo cutâneo axilar, distribuiu-se para a pele da região proximal do braço.

O nervo radial (Figura 1) apresentou-se como o mais espesso dos ramos terminais do cordão dorsal. Deixou a região axilar em sentido distal, contornando cranialmente o músculo escapuloumeral caudal, inserindo-se no terço médio do braço no espaço formado entre os músculos tríceps umeral e tríceps escapular. Neste ponto, emitiu em sentido distal um longo ramo muscular pela margem caudal do músculo tríceps escapular, continuando em posição subcutânea e lateral ao terço médio do úmero e do músculo bíceps braquial, distalmente à inserção do músculo deltoide, seguindo em direção à porção proximal do antebraço (Figura 2). A partir daí, dividiu-se em nervo cutâneo dorsal do antebraço para inervar a margem cranial do antebraço (Figura 2), em um ou dois ramos musculares direcionados para as cabeças dorsal e ventral do músculo extensor carpo radial, e nos ramos superficial e profundo, ambos posicionados superficialmente à cabeça ventral do músculo supracitado e o rádio (Figura 3).

O ramo superficial enviou pequenos ramos musculares para a cabeça ventral do músculo extensor carpo radial e para o músculo extensor digital comum, continuando até o terço distal do rádio, entre os músculos supinador e extensor alular longo, onde passou a ser subcutâneo, inervando os músculos ulnometacárpico dorsal, extensor alular curto, abdutor e adutor da álula, além dos folículos das penas posicionadas na margem caudal da mão. Por sua vez, o ramo profundo inervou os músculos extensor carpo ulnar e ectepicôndilo ulnar, além dos folículos das penas posicionadas na margem caudal da extremidade proximal antebraço.

Na distribuição do cordão ventral (Figura 1), o tronco peitoral emergiu medialmente como um de seus ramos terminais e se subdividiu igualmente em nervo peitoral cranial, direcionado para a porção cranial do músculo supracoracóideo, e nervo peitoral caudal, que se ramificou próximo ao terço médio do músculo peitoral. O tronco peitoral ainda enviou o delgado nervo coracobraquial, que supriu os músculos coracobraquial caudal e escapuloumeral caudal.

O nervo medianoulnar partiu latero-distalmente do cordão ventral, como seu ramo terminal mais espesso. Em seu trajeto em direção ao braço, contornou cranialmente o terço distal do músculo escapuloumeral caudal, onde enviou logo em seguida o delgado nervo bicipital para o músculo bíceps braquial, até atingir a face medial do músculo tríceps umeral, passando a correr em direção à face medial do terço proximal do antebraço, onde se dividiu nos nervos mediano e ulnar, próximo à inserção do músculo bíceps braquial (Figura 1).

Imediatamente após sua divisão, o nervo mediano enviou ramos para a articulação úmero-rádioulnar e para os músculos braquial e pronador superficial e, novamente, subdividiu-se em ramos superficial e profundo (Figura 4). Seu ramo superficial correu em sentido caudodistal, entre os ventres dos músculos pronadores superficial e profundo (Figura 4), onde inervou o músculo flexor digital profundo e a pele da face medial da porção distal do antebraço e proximal da mão. $\mathrm{O}$ ramo profundo seguiu em direção distal à margem cranial da ulna, até atingir o espaço interósseo, assumindo posição subcutânea, para ultrapassar o retináculo flexor, inervando na mão os músculos flexor e adutor alular e flexor digital superficial, além das superfícies caudal e palmar da pele.

O nervo ulnar (Figuras 1 e 4) seguiu pela face medial da extremidade proximal do antebraço, onde enviou pequenas ramificações para os músculos pronadores superficial e profundo, flexor digital profundo e flexor ulnar do carpo, além de inervar os folículos das penas primárias e secundárias da margem caudal do antebraço. 


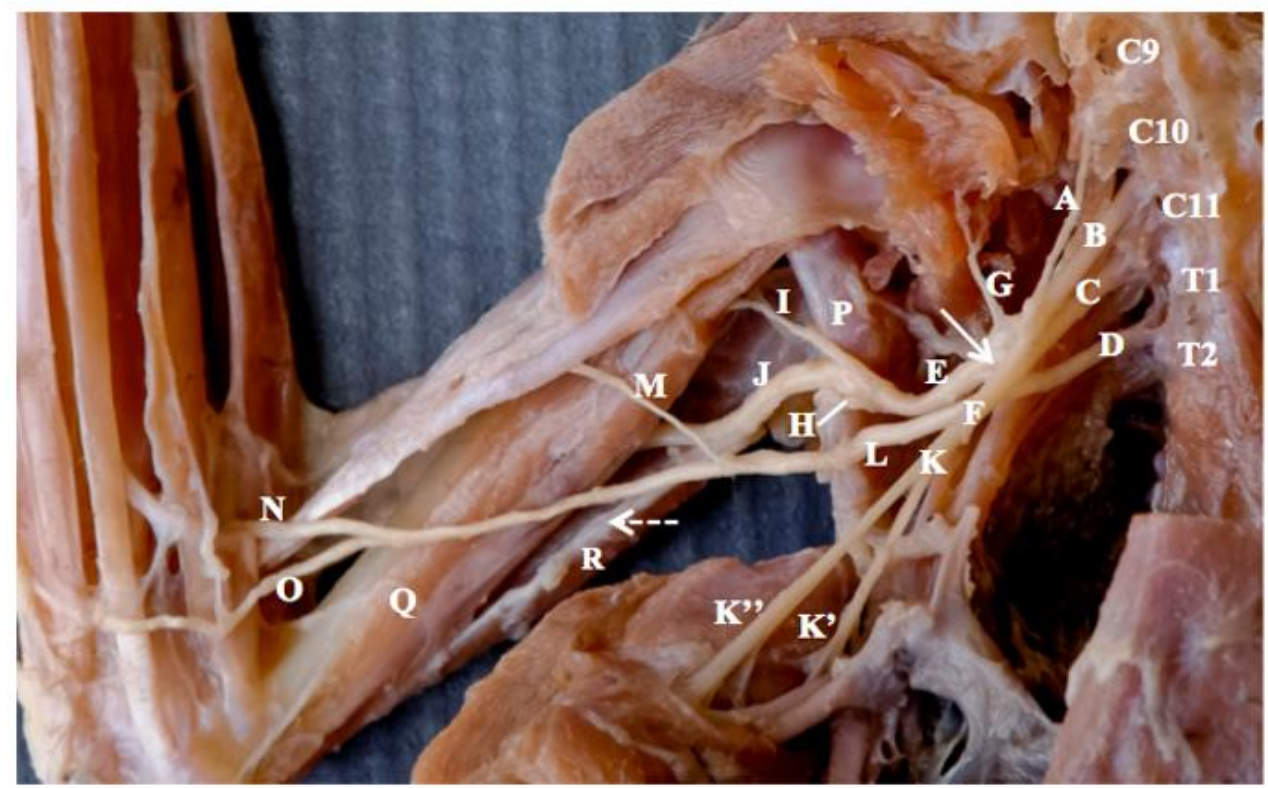

Figura 1: Macrofotografia da origem e distribuição do plexo braquial de papagaio verdadeiro, com onze vértebras cervicais, vista medial. Estão identificados os ramos ventrais dos nervos espinhais C9 e C10 (Tronco 1, A), C10 e C11 (Tronco 2, B), C11 e T1 (Tronco 3, C) e T1 e T2 (Tronco 4, D), que formaram um tronco comum (seta), subdividido em cordão dorsal (E) e ventral (F). Podem ser observados os nervos supracoracóideo $(\mathrm{G})$, anconeal $(\mathrm{H})$, axilar (I), radial (J) e seu ramo muscular (seta tracejada), tronco peitoral $(\mathrm{K})$ e seus nervos peitorais cranial (K') e caudal (K'), nervo medianoulnar (L), nervo bicipital (M), nervo mediano $(\mathrm{N})$ e nervo ulnar (O), além dos músculos escapuloumeral caudal $(\mathrm{P})$, tríceps umeral $(\mathrm{Q})$ e tríceps escapular $(\mathrm{R})$.

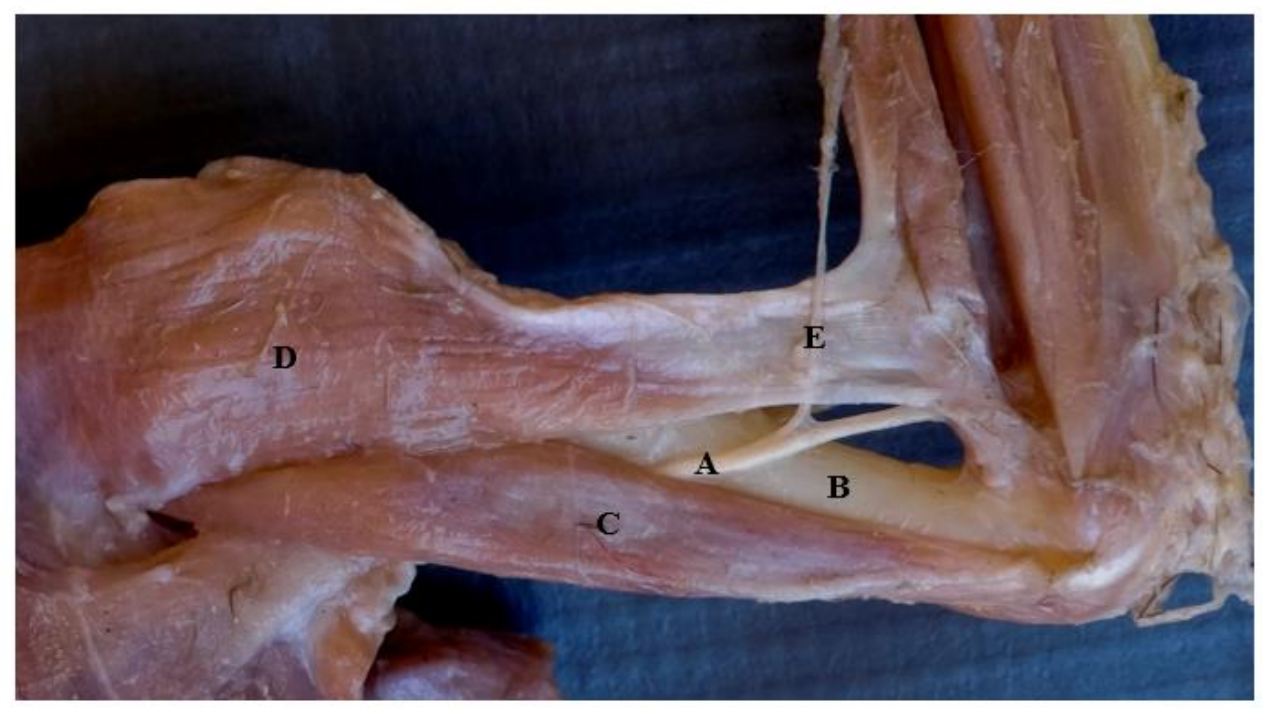

Figura 2: Macrofotografia do braço e região proximal do antebraço de papagaioverdadeiro, vista lateral. Observe que na face lateral do terço médio do braço, o nervo radial (A) passou superficialmente ao úmero (B), entre os músculos tríceps escapular (C) e deltoide (D), onde enviou o nervo cutâneo dorsal do antebraço (E), que seguiu superficialmente ao tendão de inserção do músculo deltoide e continuou em direção à face craniolateral do antebraço. 


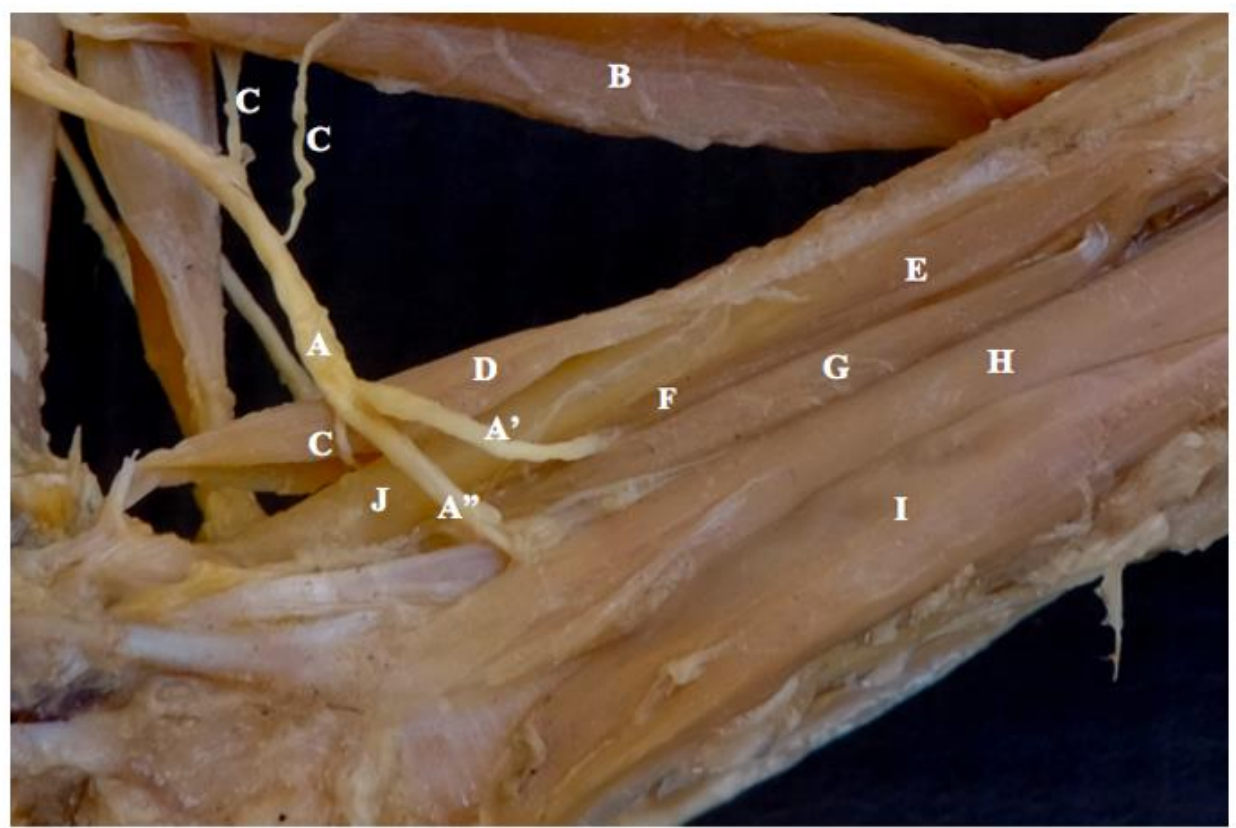

Figura 3: Macrofotografia da extremidade proximal do antebraço de papagaioverdadeiro, vista lateral. Para visualização da divisão do nervo radial (A) em ramos superficial (A') e profundo (A"), foi necessário o rebatimento da cabeça dorsal do músculo extensor carpo radial (B). Estão identificados os ramos musculares do nervo radial (C), a cabeça ventral do músculo extensor carpo radial (D), os músculos extensor alular longo (E), supinador (F), extensor digital comum $(G)$, extensor carpo ulnar $(H)$ e ectepicôndilo ulnar (I), bem como o osso rádio (J).

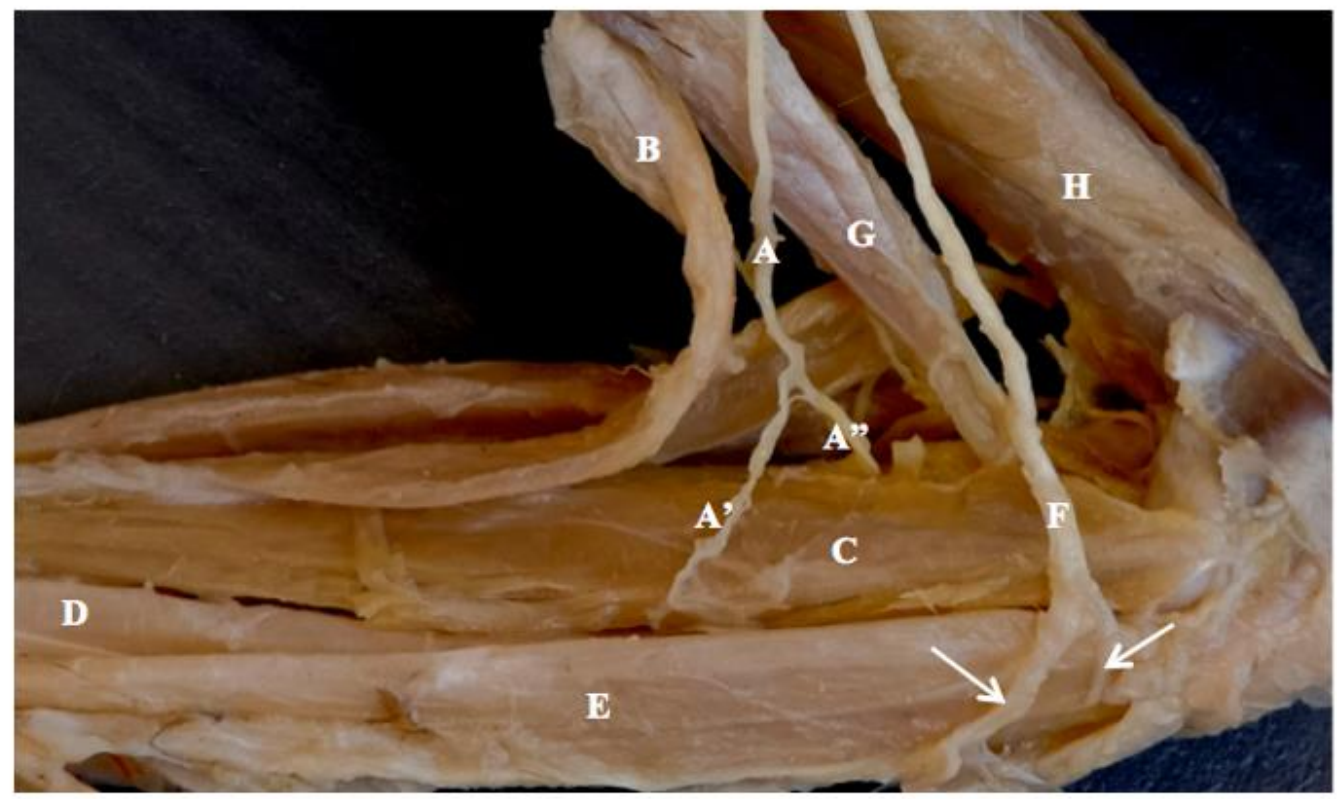

Figura 4: Macrofotografia da extremidade proximal do antebraço de papagaioverdadeiro, vista medial. Para visualização da divisão do nervo mediano (A) em ramos superficial (A') e profundo (A"), foi necessário o rebatimento do músculo pronador superficial (B). Estão identificados os músculos pronador profundo (C), flexor digital profundo (D) e flexor ulnar do carpo (E), além do nervo ulnar (F) e seus ramos musculares (setas), os músculos bíceps braquial $(\mathrm{G})$ e tríceps umeral $(\mathrm{H})$. 


\section{Discussão}

A literatura tradicional trouxe informações importantes sobre a origem e a distribuição do plexo braquial em galinhas (Gallus galus domesticus), fato que pode explicar o uso dessa espécie como referência para a descrição detalhada da anatomia macroscópica e de seu bloqueio anestésico ${ }^{(6,13)}$. No entanto, a falta de maiores estudos sobre as variações anatômicas e fisiológicas observadas para os diferentes grupos de aves, principalmente as silvestres, ainda geram dificuldades para a localização e o acesso do plexo braquial, podendo levar a falhas durante o bloqueio anestésico, além da possibilidade de sobredose da substância anestésica localmente utilizada ${ }^{(4)}$.

Isto pode ser exemplificado nos papagaios dissecados, já que os grandes músculos peitorais cobriram a porção proximal do plexo braquial, principalmente os dois cordões nervosos (dorsal e ventral) e seus primeiros ramos, dificultando sua visualização transcutânea e até mesmo sua palpação ${ }^{(14)}$. Devido a essa característica, o bloqueio deste segmento do plexo braquial poderá ser feito apenas introduzindo uma agulha mais profundamente, sem a garantia de que o anestésico local irá alcançá-lo ${ }^{(9)}$.

No terço médio do braço, os nervos radial e medianoulnar encontraram-se superficialmente ao úmero e sem cobertura muscular, disposição que neste caso facilita a visualização transcutânea para a realização de procedimentos anestésicos, mas também aumenta a chance de ruptura quando da ocorrência de fraturas umerais, devido à intimidade dos nervos com a diáfise do osso ${ }^{(11,15,16)}{ }^{\text {. Não }}$ obstante, praticamente não existem relatos de bloqueios anestésicos específicos desses nervos, os quais podem ser úteis para o tratamento de dor neuropática em aves ${ }^{(17)}$.

Em dezenove papagaios dissecados, o plexo braquial foi originado dos ramos ventrais dos últimos nervos espinhais cervicais (C9 a C11) e dos primeiros torácicos (T1 e T2), ou, como visto em dois outros exemplares, oriundo dos espaços intervertebrais C9 a C12 e primeiro torácico (T1), mas sempre com a formação de quatro troncos nervosos. Essas descrições assemelharam-se àquelas feitas para urubus (Coragyps atratus) e araras Canindé (Ara ararauna), apesar de os troncos relatados terem sido oriundos, respectivamente, dos segmentos C10 a T2 e C11 a T2, sendo possível a ocorrência de variações entre animais de mesma espécie ${ }^{(10,11,18)}$.

Vale ressaltar que em apenas um papagaio foram encontrados três troncos nervosos (C9 a T1), o mesmo número observado para o peru (Meleagris gallopavo) (C12 a T2), o esmerilhão (Falco columbarius) e o pombo doméstico (Columba livia), mas com a diferença de que os dois últimos foram os únicos que tiveram o plexo braquial formado exclusivamente por nervos espinhais cervicais (C11 a C13 e C13 a C16, respectivamente) ${ }^{(18-20)}$.

De maneira geral, o plexo acessório não foi encontrado no avestruz (Struthio camelus) ${ }^{(21)}$, como para todas as aves dissecadas e a maioria das espécies comparadas ${ }^{(10,11,19)}$. Vale ressaltar que a presença deste plexo não interfere com a área de inervação determinada para os outros troncos formadores do plexo braquial, já que supre principalmente os músculos serrátil e romboide ${ }^{(19,20)}$. A variabilidade observada para os segmentos de origem das raízes do plexo braquial nas espécies comparadas está relacionada com o número de vértebras cervicais, característica anatômica que varia nas aves ${ }^{(22,23)}$, como verificado em dois papagaios verdadeiros que possuíam doze vertebras cervicais.

Da mesma forma que nas aves analisadas, a literatura específica consultada foi unânime ao relatar a união dos troncos nervosos formadores do plexo braquial em um tronco comum, com separação em 
cordões dorsal e ventral, cujos ramos supriram respectivamente os músculos dos compartimentos extensor e flexor do membro torácico, e pele sobrejacente ${ }^{(10)}$. Especificamente para o papagaio verdadeiro, a ramificação do cordão dorsal foi semelhante ao encontrado no esmerilhão e na arara Canindé, pois apresentou o nervo radial como seu ramo terminal, e os nervos axilar e anconeal como ramos diretos ${ }^{(10,19)}$, enquanto que, no peru e no urubu, o nervo anconeal foi derivado diretamente do nervo radial ${ }^{(10,18)}$, estando ausente em pombos, já que sua área de inervação foi assumida pelo ramo superficial do nervo radial $^{(20)}$.

Diferentemente do anterior, o cordão ventral do papagaio verdadeiro apresentou ramificação semelhante apenas à do pombo doméstico e do esmerilhão, pois se ramificou em tronco peitoral e nervo medianoulnar ${ }^{(19,20)}$, mas diferenciou-se do urubu, do peru e do avestruz por não apresentar o nervo bicipital nesta divisão ${ }^{(10,18,21)}$. Como nas araras Canindé, o nervo bicipital foi descrito como ramo direto do nervo medianoulnar ${ }^{(11)}$.

Ainda nas araras Canindé, o cordão ventral apresentou o nervo coracobraquial como um de seus ramos, fato não relatado para as outras espécies comparadas, até porque, como visto nos papagaios dissecados e no esmerilhão, foi originado diretamente do tronco peitoral, além de não ser reportado para o peru e o urubu, já que o nervo bicipital provavelmente assumiu sua área de inervação, pois foi o único que enviou ramos para o músculo coracobraquial ${ }^{(10,11,18)}$. Também, deve-se relatar o fato de que Franceschi et al. ${ }^{(20)}$ não fizeram referência aos nervos bicipital e coracobraquial, não sendo possível inferir quais nervos assumiram suas respectivas áreas de inervação.

Quanto à forma de distribuição dos nervos do plexo braquial para as regiões de antebraço e mão, ficou claro que mesmo com a grande semelhança observada para a origem e seu segmento proximal nas espécies comparadas, ela irá depender diretamente do número, da topografia e das variações anatômicas específicas encontradas nos grupos musculares flexores e extensores, pois adequações quanto aos movimentos do membro torácico são necessárias para o desenvolvimento do hábito de vida de cada espécie ${ }^{(24)}$.

\section{Conclusões}

A origem do plexo braquial do papagaio verdadeiro é muito semelhante àquela encontrada em outras aves, sendo que variações quanto aos segmentos da medula espinhal que fornecem as raízes são esperadas e podem estar relacionadas com o número de vértebras cervicais em cada espécie. A distribuição dos nervos oriundos do plexo braquial pode variar de acordo com o número e a topografia dos músculos nas diferentes espécies de aves comparadas, principalmente nas regiões de antebraço e mão.

\section{Referências}

1. Galetti M, Guimarães Junior PR, Marsden SJ. Padrões de riqueza, risco de extinção e conservação dos psitacídeos neotropicais. In: Galetti, M., Pizo, MA. Ecologia e conservação de psitacídeos no Brasil. Belo Horizonte: Melopsittacus Publicações Científicas; 2002. p.17-26.

2. Medeiros LB, Carrijo AS, Negrini JM, Onselen VJV. Utilização de prebiótico na alimentação de filhotes de papagaio verdadeiro (Amazona aestiva) em processo de reabilitação. Archives of Veterinary Science. 
2006; 11(3): 62-68.

3. Guimarães LD, Moraes AN. Anestesia em aves: agentes anestésicos. Ciência Rural. 2000; 30(6):10731081.

4. Figueiredo JP, Cruz ML, Mendes GM, Marucio RL, Riccó RH, Campagnol D. Assessment of brachial plexus blockade in chickens by an axillary approach. Veterinary Anaesthesia and Analgesia. 2008; 35: 511518.

5. Mostachio GQ, Oliveira LD, Carciofi AC, Vicente WRR. The effects of anesthesia with a combination of intramuscular xylazine-diazepam-ketamine on heart rate, respiratory rate and cloacal temperature in roosters. Veterinary Anaesthesia and Analgesia. 2008; 35: 232-236.

6. Soresini GCG, Pimpão CT, Vilani RGD’oC. Bloqueio do plexo braquial em aves. Revista Acadêmica: Ciências Agrárias e Ambientais. 2013; 11(1):17-26.

7. Cardozo LB, Almeida RM, Fiuza LC, Galera PD. Brachial plexus blockade in chickens with $0.75 \%$ ropivacaine. Veterinary Anaesthesia and Analgesia. 2009; 36: 396-400.

8. Bitencourt EH, Padilha VS, Lima MPA, Beier SL, Moraes NA, Oleskovicz N. Efeitos sedativos da associação de Cetamina e Midazolam administrados pela via intranasal ou intramuscular em papagaio (Amazona aestiva e Amazona vinacea). Pesquisa Veterinária Brasileira. 2013; 33(9): 1125-1129.

9. Vilani RGOC, Ferreira FM, Lange RR, Samonek JFV. Brachial plexus block in birds. Exotic. 2006; 8(2): 27-32.

10. Moreira PRR, Souza WM, Souza NTM, Carvalho RG, Custódio AA. Arranjos configurados pelos nervos do plexo braquial no urubu (Coragyps atratus foetens-Linnaeus, 1758). Brazilian Journal of Veterinary Research and Animal Science. 2009; 46(2): 144-151.

11. Filho KA, Rodrigues MN, Fonseca ET, Leandro RM, Pasqualetti VB, Miglino MA. Origem, distribuição e inserção dos nervos do plexo braquial em Araras Canindé (Ara ararauna, Linnaeus, 1758). Biotemas. 2014; 27(3): 157-166.

12. Baumel JJ. Handbook of avian anatomy: nomina anatomica avium. 2nd ed. Cambridge: Nuttall Ornithological Club, 1993. 779p. Disponível em http://www.oucom.ohiou.edu/dbmswitmer/Downloads/1993_Baumel_\&_Witmer_NAA-2_Osteologia.pdf, Acesso em abril 2015.

13. Nickel R, Schummer A, Seiferle E. Anatomy of the domestic birds. Berlin: Parey,1977. p. 131-139.

Disponível em http://www.ncbi.nlm.nih.gov/pmc/articles/PMC1789617/pdf/canvetj00323-0028.pdf, Acesso em abril de 2015.

14. Cunha AFC, Strain GM, Rademacher N, Schnellbacher R, Tully, TN. Palpation and ultrasound-guided brachial plexus blockade in Hispaniolan Amazon Parrots (Amazona ventralis). Veterinary Anaesthesia and Analgesia. 2013; 40: p.96-102.

15. Shell L, Richards M, Saunders G. Brachial plexus injury in two red-tailed hawks (Buteo jamaicensis). Journal of Wildlife Disease.1993; 29(1): p.177-179.

16. Bolson J, Schossler JEW. Osteossíntese em aves: revisão bibliográfica. Arquivo de Ciências Veterinárias e Zoologia da Unipar. 2008; 11(1): p. 55-62.

17. Shaver SL, Robinson NG, Wright BD, Kratz GE, Johnston MS. A multimodal approach to management of suspected neuropathic pain in a Prairie Falcon (Falco mexicanus). Journal of Avian Medicine and Surgery. 2009; 23(3): p.209-213.

18. Demirkan AÇ. Anatomical structure of the brachial plexus in the Merlin (Falco columbarius). Anatomia, Histologia, Embryologia. 2014; 43: p.31-35. 
19. Moreira PRR, Souza WM, Souza NTM, Carvalho RG, Custódio AA. Arranjos configurados pelos nervos do plexo braquial no peru (Meleagris gallopavo-Linnaeus, 1758). ARS Veterinária. 2005; 21(3): p.296-302.

20. Franceschi RC, Souza DAS, Rovenci M, Pereira MAM. Estudo da inervação e vascularização do membro torácico de Columbia livia. Brazilian Journal of Veterinary Research and Animal Science. 2009; 46(6): p. 507-514.

21. Pospieszny N, Pachulska P, Paździor K, Wustinger J. Nerves of thoracic limb of the ostrich (Struthio camelus.). Electronic Journal of Polish Agricultural Universities [periódico na Internet]. 2009; 12(4). Disponível em: http://www.ejpau.media.//volume12/issue4/art-08.html.

22. Galis F. Why do almost all mammals have seven cervical vertebrae? Developmental constraints, hox genes, and cancer. Journal of Experimental Zoology (Mol Dev Evol). 1999; 285: 19-26.

23. Krings M, Nyakatura JA, Fischer MS, Wagner H. The Cervical Spine of the American Barn Owl (Tyto furcata pratincola): I. Anatomy of the Vertebrae and Regionalization in Their S-Shaped Arrangement. Plos One [periódico na Internet]. 2014; 9(3). Disponível em: http://journals.plos.org/plosone/article?id=10.1371/journal.pone.0091653.

24. Swinebroad JA. Comparative study of the wing myology of certain passerines. American Midland Naturalist. 1954; 51(2): 488-514. 